Review Article

\title{
Selenium, selenoprotein P, and Alzheimer's disease: is there a link?
}

\author{
Nikolay Solovyev ${ }^{\mathrm{a}, *}$, Evgenii Drobyshev ${ }^{\mathrm{b}}$, Geir Bjørklund ${ }^{\mathrm{c}, *}$, Yaroslav Dubrovskii ${ }^{\mathrm{a}}$, \\ Roman Lysiuk $^{\mathrm{d}}$, Margaret P. Rayman ${ }^{\mathrm{e}}$
}

a St. Petersburg State University, Institute of Chemistry, St. Petersburg, Russian Federation

${ }^{\mathrm{b}}$ Universität Potsdam, Institut für Ernährungswissenschaft, Potsdam, Germany

c Council for Nutritional and Environmental Medicine, Mo i Rana, Norway

d Department of Pharmacognosy and Botany, Danylo Halytsky Lviv National Medical University, Lviv, Ukraine

e Department of Nutritional Sciences, University of Surrey, Guildford, UK

\section{A R T I C L E I N F O}

\section{Keywords:}

Alzheimer's disease

Neurodegeneration

Selenium

Selenoprotein P

Brain

Oxidative stress

Redox regulation

Human studies

Model studies

Supplementation

Amyloid-beta

Trace elements

\begin{abstract}
A B S T R A C T
The essential trace element, selenium (Se), is crucial to the brain but it may be potentially neurotoxic, depending on dosage and speciation; Se has been discussed for decades in relation to Alzheimer's disease (AD). Selenoprotein P (SELENOP) is a secreted heparin-binding glycoprotein which serves as the main Se transport protein in mammals. In vivo studies showed that this protein might have additional functions such as a contribution to redox regulation. The current review focuses on recent research on the possible role of SELENOP in AD pathology, based on model and human studies. The review also briefly summarizes results of epidemiological studies on Se supplementation in relation to brain diseases, including PREADViSE, EVA, and AIBL. Although mainly positive effects of Se are assessed in this review, possible detrimental effects of Se supplementation or exposure, including potential neurotoxicity, are also mentioned. In relation to AD, various roles of SELENOP are discussed, i.e. as the means of Se delivery to neurons, as an antioxidant, in cytoskeleton assembly, in interaction with redox-active metals (copper, iron, and mercury) and with misfolded proteins (amyloid-beta and hyperphosphorylated tau-protein).
\end{abstract}

\section{Introduction}

Selenoprotein P (SELENOP [1], also known as SelP, SePP, SePP1, and SeP) is one of 25 human selenoproteins [2] containing the 21st proteinogenic amino acid selenocysteine (Sec). SELENOP is the sole human selenoprotein that can contain up to ten Sec residues [3,4] and is considered to be the main selenium (Se) transport protein in mammals [5]. Se is a trace element essential for humans that, while being crucial to the brain, can also be highly neurotoxic depending on dosage and speciation $[4,6,7]$. Although the content of Se in the brain is only some $2.3 \%$ of the total amount of Se in the human body [8], the brain is highly protected from Se depletion owing to the hierarchical structure of Se metabolism [9]. The region-specific pattern for brain Se deposition has been found using radioactive ${ }^{75} \mathrm{Se}$-labeled selenite. The brain uptake of labeled ${ }^{75}$ Se-selenite was shown to start only after the appearance of plasma ${ }^{75}$ Se-SELENOP, differentiating the brain from other tissues [10]. Interestingly, with the injection of ${ }^{75}$ Se-labeled SELENOP, the accumulation of ${ }^{75} \mathrm{Se}$ in the Se-depleted rat brain two hours later was five-times greater $(p<0.05)$ than in Se-sufficient controls [11], while total body turnover for ${ }^{75} \mathrm{Se}$ was insignificantly affected by Se status. Under low Se supply, the brain tends to store Se at a nearly constant level [12]. Se deprivation causes irreversible damage to neuronal tissue $[12,13]$. Such hierarchy of Se homeostasis is good evidence for its essential functions in the brain [14] and SELENOP is thought to take a central part in maintaining such hierarchy [9]. Indeed, the impairment of brain Se homeostasis or severe Se deficiency causes highly detrimental neurological outcomes and can become lethal in extreme cases $[4,13]$. Se seems to be involved in most molecular mechanisms related to neurodegeneration pathology and specifically in Alzheimer's disease (AD); these include redox pathways, myelopathies, signal transduction and cytoskeleton assembly $[15,16]$.

SELENOP is a potentially multifunctional protein with both

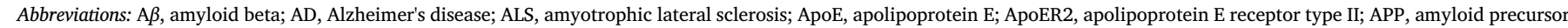

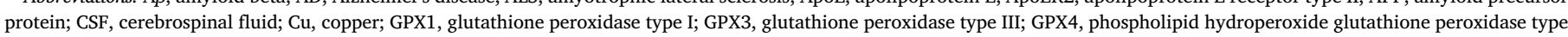

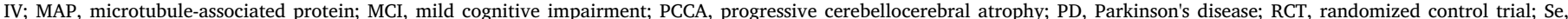

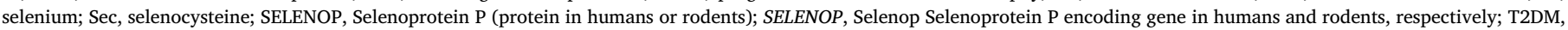
type II diabetes mellitus; Zn, zinc

* Corresponding authors.

E-mail addresses: n.solovyev@spbu.ru (N. Solovyev), bjorklund@conem.org (G. Bjørklund). 
enzymatic and Se-transport activities that plays a central role in body Se transport and maintaining tissue Se hierarchy [17]. Plasma/serum SELENOP concentration is therefore considered to be a more accurate biomarker of Se status than total serum Se or plasma/serum glutathione peroxidase (GPX3) activity $[18,19]$. SELENOP plays an import role in the transport of Se to the brain for the synthesis of essential selenoproteins [16] such as GPX and thioredoxin reductase (TrxR) [20]. Currently, SELENOP is considered to be an indicator selenoprotein for the saturation of Se nutritional requirements $[8,21]$. However, SELENOP functions are not limited solely to Se transport [19]; it contains a redox motif and exhibits certain antioxidant properties [12,22] contributing to redox regulation. Experiments with transgenic mice showed that decreasing brain Se by genetic inactivation of SELENOP, or its receptor, apolipoprotein E-receptor type II (ApoER2) [23,24], caused spontaneous neurological impairment and degeneration. AD is closely associated with protein misfolding [25,26], leading to the formation of molecules that cause neuronal cell damage and synaptic dysfunction. Oxidative stress is an important molecular mechanism implicated in $\mathrm{AD}$ and other neurodegenerative conditions [27-29], hence the selenoproteins are potentially capable of counteracting $\mathrm{AD}$ development, owing to their antioxidant properties.

There is an age-associated increase in gene expression of SELENOP [30] which may indicate an increased demand for Se in the ageing organism. Moreover, in $\mathrm{AD}$ [31] and other neurodegenerative states [32], the SELENOP gene appears to be up-regulated even more. This fact and the neurological phenotype of Selenop-knockout animals implicate SELENOP in cognition and, in particular, give it a possible role in AD. Interestingly, in the brain, SELENOP uses the same receptor as apolipoprotein E (ApoE); ApoE polymorphisms are considered to be the strongest genetic risk factor for $\mathrm{AD}[33,34]$. The current review focuses on the recent findings that suggest the involvement of SELENOP in AD pathology, based on model and human studies. Although mainly positive aspects of SELENOP are featured in this review, we also comment on the detrimental effects of excessive Se supplementation or exposure, including potential neurotoxicity, elevated risk of type II diabetes mellitus (T2DM), certain malignancies and amyotrophic lateral sclerosis (ALS) [35,36], with T2DM having SELENOP as a candidate protein that mediates impaired insulin response [37-39].

\section{Biochemistry and functions of SELENOP}

SELENOP is a secreted heparin-binding glycoprotein [40], mainly supplied to the blood by hepatocytes [12,41,42]. SELENOP is also present in extra-hepatic tissues, most notably in the brain [43] and testes [24]. Although SELENOP is a secreted protein, its intracellular presence was reported for neurons [43], testicular Leydig cells [44], adipocytes [45], and pancreatic $\beta$-cells [46]. SELENOP is the most abundant selenoprotein [47] in cerebrospinal fluid (CSF) which has been shown to have a central role in brain-Se homeostasis [9]. SELENOP may be produced by astrocytes, at least in vitro $[40,48]$. The liver is a central regulator of body Se homeostasis, directing it to either selenoprotein synthesis or towards excretion [19]; Fig. 1 depicts body Se transport with SELENOP being the main Se-carrier to the brain. However, additional Se transport to neuronal tissue may be attributed to selenosugars [49] and/or other low molecular mass Se-species [47]. Selenoprotein biosynthesis is regulated by a highly sophisticated system that operates at transcriptional, translational and post-translational levels [2], depending on the availability of Se [50]. Interestingly, recent in vitro experiments by Turanov et al. [17] have shown that cysteine (Cys) may replace Sec in SELENOP under Se restriction, whereas normally in human blood plasma, up to $8 \%$ (average of $4 \%$ ) of the Sec residues in SELENOP are replaced by Cys. More details on selenoprotein biosynthesis machinery and functions are available elsewhere [5,19,51-55].

SELENOP has a significant role in delivering Se to the brain by binding to a surface receptor ApoER2, a member of the lipoprotein

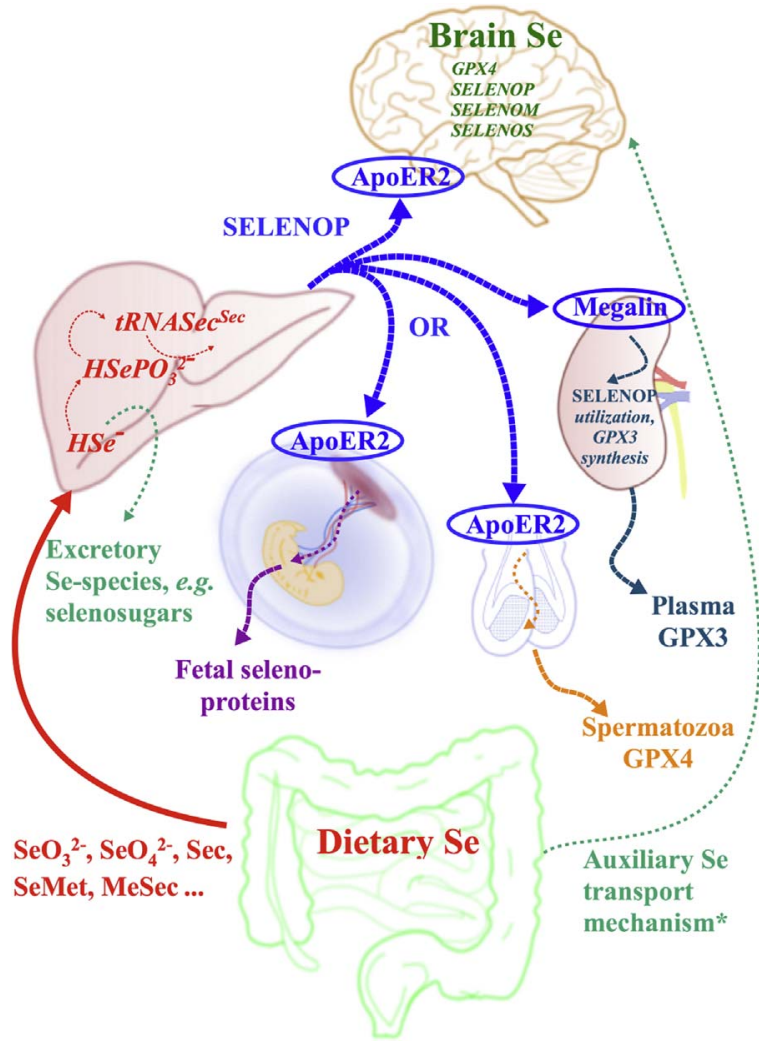

Fig. 1. Body Se transport scheme [12,56,57]. Abbreviations: ApoER2 - apolipoprotein receptor type II, GPX3 - glutathione peroxidase type III, GPX4 - glutathione peroxidase type IV, Sec - selenocysteine, MeSec - methylselenocysteine, SELENOM - selenoprotein M, SELENOP - selenoprotein P, SELENOS - selenoprotein S; *- auxiliary brain Se transport mechanism, independent of SELENOP, possibly related to selenosugars [49] and other low molecular mass Se-species [47].

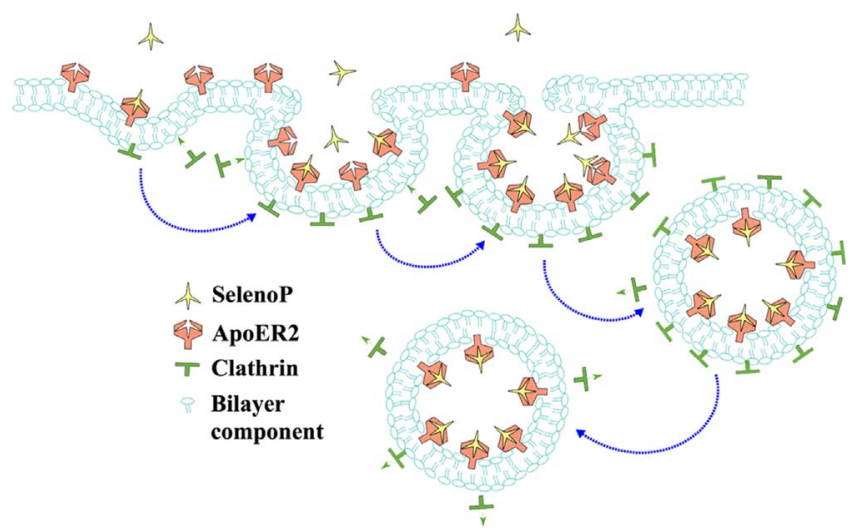

Fig. 2. Clathrin-dependent endocytosis of SELENOP via ApoER2.

receptor family, through clathrin-dependent endocytosis (Fig. 2) [58]. Mice that cannot synthesize SELENOP develop abnormal movements, spasticity, and spontaneous seizures [59]. High amounts of SELENOP are found in the brain $[54,60,61]$. Interestingly, the absence of SELENOP (but not of selenocysteine lyase, the enzyme that retrieves Se from the selenoproteins after proteolysis), has been found to result in severe neurological dysfunction [62]. It seems that the central nervous system (CNS) relies much more on an external Se supply rather than on Se recycling. Thus, SELENOP is thought to play a significant role in neuronal survival but is also associated with AD pathology [60]. Astrocytes appear to secrete SELENOP that neurons subsequently take up via the ApoER2 [54]. Interestingly, for the kidney, the main tissue that produces and secretes GPX3 [63], SELENOP uptake is not associated 
with ApoER2 but with another lipoprotein receptor - megalin [64] (Fig. 1).

ApoE has been shown to have a primary role in $\mathrm{AD}$ development and progression [65] and it is now fully established that the ApoE- $\varepsilon 4$ allele is a strong hereditary risk factor for AD [33]. Since ApoE shares the same brain receptor as SELENOP, its mutations may affect Se uptake by the brain; however, to the best of our knowledge, there is, as yet, no such direct evidence. Additionally, the Se species, selenate [66-68] and selenomethionine [69] were reported to have an attenuating effect on tau hyperphosphorylation, which is characteristic of AD [70,71]. Thus, Du et al. proposed that SELENOP might either provide Se to inhibit the abnormal phosphorylation of tau-protein directly or to suppress ROSmediated tau phosphorylation [72]. The delivery hypothesis is to some extent supported by the speciation findings of Michalke and Berthele [73], later confirmed by Solovyev et al. [47], that showed that selenate was formed in the CSF as a degradation product of SELENOP and probably of other selenoenzymes. It should be noted, however, that in vitro observations of stored CSF are unlikely to reflect real brain biochemistry.

The SELENOP-encoding gene is known to have several single nucleotide polymorphisms (SNPs) [74] which are relevant to the protein level and function [75,76]. Méplan et al. [75] performed SNP screening in 20 individuals and reported two common SNPs related to G to A substitution in SELENOP mRNA. The first SNP corresponds to the amino acid Ala to Thr replacement at the position 234 (Ala234Thr, rs3877899). The second SNP is present in the $3^{\prime}$-untranslated region (UTR) (rs7579) [77]. The authors carried out an intervention study (75 volunteers, 6-week supplementation with $100 \mu \mathrm{g} \mathrm{Se} / \mathrm{day}$, washout period of 6 weeks) to evaluate the role of SELENOP gene polymorphisms in Se metabolism. A significant alteration of plasma Se concentration and other Se-status biomarkers (plasma SELENOP, plasma GPX3, erythrocyte thioredoxin reductase type I and lymphocyte GPX) was found for individuals, carrying both rs3877899 and rs7579 SNPs of SELENOP. The authors have suggested that the observed differences may relate to altered post-translational modification in the case of the rs3877899 SNP, whereas rs7579 may influence SELENOP synthesis, affecting the SECIS region of mRNA. Interestingly, SELENOP SNPs were shown to be associated with a change in the ratio of $50-$ to $60-\mathrm{kDa}$ SELENOP isoforms in blood plasma [77]. No effect of rs3877899 and rs7579 SNPs on Se status or oxidative stress parameters was found in a Brazilian population with mild cognitive impairment (MCI) [76].

Originally, SELENOP neuroprotective functions were considered to be limited to Se supply to the brain to produce primary antioxidant selenoproteins, such as glutathione peroxidase (GPX)1 [78-80] and GPX4 [81-83], methionine sulfoxide reductase B [84] and selenoprotein M (SELENOM) [85-87]. Another selenoprotein, selenoprotein $\mathrm{S}$ (SELENOS), associated with the endoplasmic reticulum, also appears to be capable of decreasing tau phosphorylation [88]. However, at present the role of SELENOP in the brain is considered as more than just a Secarrier owing to its redox activity and effective interactions with different bioactive molecules and metal ions.

Human SELENOP has two histidine-rich domains [17] which may account for its capacity to bind to transition metals, e.g. copper $(\mathrm{Cu})$ and iron $(\mathrm{Fe})$. These metals are implicated in neurodegenerative pathology, including that of AD $[29,89,90]$. Indeed, some authors have ascribed the neuroprotective properties of SELENOP to its metal-binding properties. The redox motifs (UXXC and CXXC) and the histidine-rich domain of SELENOP are known as bivalent cation-binders (e.g., of $\mathrm{Cu}^{2+}$ and $\mathrm{Zn}^{2+}$ ) [91].

\section{SELENOP interaction with bioactive components involved in Alzheimer's disease pathology}

SELENOP, as a chemically active protein, containing multiple Sec and cysteine residues, interacts with a number of substances that may be related to brain pathology. First of all, its metal-binding capacities are widely known $[92,93]$. Importantly, amyloid- $\beta$ (A $\beta$ ) also has a strong affinity for metals, binding redox-active essential metals like $\mathrm{Cu}$ [94-98] and Fe [97] as well as Zn [91,96,97,99,100], which may alter $\mathrm{Cu}$ and Fe binding by protein homeostasis $[7,26]$. SELENOP also binds to toxic metals such as cadmium (Cd) $[99,101]$ and mercury (Hg) [102]. Mis-compartmentalization of metals such as $\mathrm{Cu}, \mathrm{Zn}$, and Fe occurs in the AD brain [88], causing detrimental neuronal outcomes [103], though the total metal amount remains unchanged. Accordingly, an attractive working hypothesis might be the formation of ternary complexes between metal cations, $A \beta$ and SELENOP. Such complexes might perhaps be less toxic than $A \beta$-metal complexes alone, owing to tight binding of redox-active ions by Sec residues of SELENOP and/or its histidine-rich domain. However, since $\mathrm{A} \beta$ is presumably much more abundant in the AD brain than SELENOP, the most important effect might be the binding of Se such that it is unavailable for normal incorporation into selenoproteins. Since $\mathrm{Cu}$ is found relatively abundantly in $\mathrm{A} \beta$ [79] and $\mathrm{Cu}^{2+}$ binds very strongly to Sec residues, [89], a ternary complex between $\mathrm{A} \beta, \mathrm{Cu}^{2+}$, and SELENOP might be a plausible candidate for the co-localization with $\mathrm{A} \beta$ in $\mathrm{AD}$ brains. In particular, in mice neuroblastoma N2A cells $\mathrm{Cu}^{+} / \mathrm{Cu}^{2+}$ promotes aggregation of tau and increases its cytotoxicity, compared to tau alone [104]. This causes a decrease of microtubule-associated protein 2 (MAP2) concentration, mitochondrial density, and mobility. SELENOP was shown to suppress and even reverse this process significantly [104]. The decrease of MAP2 concentration leads to the dysfunction of the microtubule assembly and therefore to the disturbance of cell shape and polarity. The effect of SELENOP on tau aggregation also maintains MAP2 which supports neuronal signal transduction. SELENOP attenuates $\mathrm{Cu}$-induced $\mathrm{A} \beta$ aggregation, but the model aggregates differ from those present in actual $\mathrm{AD}$-lesions by having a more amorphous structure. Additionally, the induction of amyloid precursor protein (APP) pathological cleavage is known to be promoted by $\mathrm{Zn}$ exposure and reversed by SELENOP [91]. Interestingly, SELENOP increases $\mathrm{A} \beta$ fibrillization rate, while decreasing the total amount of fibrillated $A \beta$. Studies with Selenopknockout murine neuroblastoma N2A cells have shown reduced viability and increased apoptotic rate with exposure to $A \beta$ oligomers [60].

Another interesting issue is the integration of SELENOP with microtubules and its involvement in cytoskeleton assembly and function. The importance of SELENOP for neuronal transport functions was demonstrated by Valentine et al. [105]; in Selenop-knockout mice fed with either Se-deficient or Se-adequate diets, enlarged dystrophic axons were observed in both groups. The axons were abnormally packed with organelles, indicating the disruption of fast axonal transport induced by dysfunction of the microtubule apparatus. Finally, acting as a Se source, SELENOP may contribute to microtubule dynamics, since other selenoproteins appear to be involved in the maintenance of microtubule stability. For instance, the depletion of $15 \mathrm{kDa}$ selenoprotein (SELENOF) in T-Rex-HeLa and Chang liver cells led to cytoskeleton abnormalities, namely blebbing and shift of $\alpha$-tubulin and F-actin localization [106]. In Selenof-knockouts, F-actin was mislocated in the cytoplasm and bleb membranes, whereas the presence of $\alpha$-tubulin was observed near nuclear and bleb membranes. The changes in tubulin and actin localization led to the disturbance of normal cytoskeletal structure and intracellular transport. In brain cells, analogous disturbances might be induced by the depletion of SELENOP, resulting in the decreased production of SELENOF and other selenoproteins.

The role of SELENOP in cytoskeleton assembly was reported as an interaction between SELENOP and the C-terminus domain of human $\alpha$ tubulin [72]. The study was conducted with an isolated domain and may not represent the actual interaction between SELENOP and microtubules. Interestingly, the C-terminal domain of $\alpha$-tubulin is associated with the regulation of microtubule assembly and can interact with cationic entities, such as tau-protein, $\mathrm{Ca}^{2+}$, and polyamines [107]. Direct binding of SELENOP or other selenoproteins with full cytoskeleton components has not been reported, to the best of our knowledge. Additionally, since SELENOP is mainly present in extracellular space, 
Table 1

Human studies on Se supplementation and/or status in AD. The studies which were already considered in Loef et al. [15] are not separately summarised.

\begin{tabular}{|c|c|c|c|c|}
\hline Study design & Se assessed/ administered & Baseline Se & Comment & Reference \\
\hline $\begin{array}{l}\text { Meta-analysis of Se in AD: } 9 \\
\text { placebo-controlled trials, } 4 \\
\text { prospective, } 4 \text { cross-sectional, } \\
\text { and } 15 \text { case-control studies. }\end{array}$ & $\begin{array}{l}\text { Different doses from } 100 \mu \mathrm{g} \text { Se } \\
\text { (form unspecified) to } 1720 \mu \mathrm{g} \\
\text { (as selenite) }\end{array}$ & $\mathrm{N} / \mathrm{A}$ & $\begin{array}{l}\text { This review summarizes most of the } \\
\text { studies from } 1986 \text { to } 2010 \text {. }\end{array}$ & Loef et al. 2011 [15] \\
\hline $\begin{array}{l}\text { EVA longitudinal cohort study of Se } \\
\text { in cognitive impairment in } \\
1166 \text { subjects aged } 60-70 \\
\text { (initial report) }{ }^{b}\end{array}$ & Baseline plasma Se & $\mathrm{N} / \mathrm{A}$ & $\begin{array}{l}\text { Significantly increased risk of } \\
\text { cognitive decline over a four-year } \\
\text { period in those with plasma } \\
\text { Se }<75.8 \mu \mathrm{g} / \mathrm{L} \text { at baseline (OR } 1.58 \text {; } \\
95 \% \text { CI } 1.08-2.31 \text { ). }\end{array}$ & Berr et al. 2000 [128] \\
\hline $\begin{array}{l}\text { EVA longitudinal cohort study of Se } \\
\text { in cognitive impairment in } \\
1166 \text { subjects aged } 60-70 \text { (final } \\
\text { reports) }\end{array}$ & $\begin{array}{l}\text { Measurement of plasma Se } \\
\text { over a 9-year period }\end{array}$ & $\begin{array}{l}\text { Baseline plasma Se } \\
(\mu \mathrm{g} / \mathrm{L}) 82.9 \pm 15.8\end{array}$ & $\begin{array}{l}\text { Cognitive decline was significantly } \\
\text { associated with the magnitude of } \\
\text { plasma Se decrease (from } \\
82.9 \pm 15.8-75.8 \pm 16.6 \mu \mathrm{g} / \mathrm{L} \text { ) over a } \\
\text { 9-year period. }\end{array}$ & $\begin{array}{l}\text { Akbaraly et al. } 2007 \\
\text { [131]; Berr et al. } 2012 \\
\text { [129] }\end{array}$ \\
\hline $\begin{array}{l}\text { Cross-sectional study of the } \\
\text { relationship between fingernail } \\
\text { Se and cognitive performance } \\
\text { in } 2000 \text { rural Chinese, aged } \geq \\
65 \mathrm{y} \text {. }\end{array}$ & Finger-nail Se concentration & $\begin{array}{l}\text { Estimated Se intake } \\
19-47 \mu \mathrm{g} / \text { day }\end{array}$ & $\begin{array}{l}\text { Lower nail Se corresponded to lower } \\
\text { cognitive-test performance. }\end{array}$ & Gao et al. 2007 [132] \\
\hline $\begin{array}{l}\text { Case-control study of } 28 \mathrm{CE} \text { cases } v s \text {. } \\
29 \text { controls, aged } 60-89 .\end{array}$ & $\begin{array}{l}\text { Se measured in plasma, } \\
\text { erythrocytes, nails, and diet }\end{array}$ & N/A & $\begin{array}{l}\text { Se concentration greater in controls } \\
\text { than in } \mathrm{AD} \text { cases, i.e. AD vs. control: } \\
\text { plasma } 32.6 \pm 22.0 \text { vs. } 51.0 \pm 21.1 \\
\mu \mathrm{g} / \mathrm{L}(\mathrm{P}<0.005) \text {; erythrocytes } \\
43.7 \pm 23.0 \text { vs. } 79.2 \pm 46.4 \mu \mathrm{g} / \mathrm{L} \\
(\mathrm{P}<0.005) ; \text { nails } 0.30 \pm 0.14 \mathrm{vs} \text {. } \\
0.40 \pm 0.13 \mu \mathrm{g} / \mathrm{g}(\mathrm{P}<0.005)\end{array}$ & Cardoso et al. 2010 [133] \\
\hline $\begin{array}{l}\text { Case-control study: } 27 \mathrm{CE} \\
\text { patients (age } 80.6 \pm 5.7 \text { ), } 17 \\
\text { MCI patients (age } 77.7 \pm 5.3 \text { ), } \\
28 \text { controls (age } 71.2 \pm 6.2 \text { ) }\end{array}$ & $\begin{array}{l}\text { Plasma and erythrocyte Se } \\
\text { concentration }\end{array}$ & N/A & $\begin{array}{l}\text { Erythrocyte Se decreased with } \\
\text { cognitive function and was lower in } \\
\text { the AD group than in controls } \\
(43.73 \pm 23.02 v s .79 .15 \pm 46.37 \mu \mathrm{g} / \\
\mathrm{L} ; \mathrm{p}=0.001) \text {. The AD group exhibited } \\
\text { the lowest plasma Se }(34.49 \pm 19.94 \\
\text { vs. MCI } 61.36 \pm 16.08, v s \text {. controls } \\
50.99 \pm 21.06 \mu \mathrm{g} / \mathrm{L}) \text {. }\end{array}$ & Cardoso et al. 2014 [134] \\
\hline $\begin{array}{l}\text { Case-control study of Se } \\
\text { concentration in serum, CSF, } \\
\text { and erythrocytes of AD, MCI } \\
\text { and control subjects (AIBL } \\
\text { study). }\end{array}$ & $\begin{array}{l}\text { Se concentration in } \\
\text { erythrocytes CSF and serum }\end{array}$ & $\mathrm{N} / \mathrm{A}$ & $\begin{array}{l}\text { Se concentration in erythrocytes from } \\
\text { AD group was significantly lower than } \\
\text { that in the control group }(68.4 \pm 5.1 \\
\text { vs. } 92.2 \pm 6.6 \mu \mathrm{g} / \mathrm{L} ; \mathrm{P}<0.001) \text {. } \\
\text { Serum or CFS Se concentration in } \mathrm{AD} \\
\text { or MCI patients and healthy controls } \\
\text { did not differ. }\end{array}$ & Cardoso et al. 2017 [135] \\
\hline $\begin{array}{l}\text { Case control study: } 173 \mathrm{CE} \text { patients } \\
\text { (age 52-87), } 85 \mathrm{CE} \text { patients } \\
\text { with vascular dementia } \\
\text { symptoms, } 54 \text { controls. }\end{array}$ & Se assessed in plasma and $\mathrm{CSF}^{b}$ & $\mathrm{~N} / \mathrm{A}$ & $\begin{array}{l}\text { Plasma Se differed between } \mathrm{AD} \text { and } \\
\text { controls }(\mathrm{P}<0.05) \text { : median } 86,87 \\
\text { and } 99 \mu \mathrm{g} / \mathrm{L} \text { for } \mathrm{AD}, \mathrm{AD} \text { with vascular } \\
\text { components and controls, } \\
\text { respectively; no difference between } \\
\mathrm{CSF} \text { concentrations. }\end{array}$ & $\begin{array}{l}\text { Gerhardsson et al. } 2008 \\
\text { [140] }\end{array}$ \\
\hline $\begin{array}{l}\text { Case-control study: } 264 \text { CE patients } \\
\text { vs. } 54 \text { controls }\end{array}$ & $\begin{array}{l}\text { Plasma and CSF Se } \\
\text { concentration measured ratio } \\
\text { calculated }\end{array}$ & No values given & $\begin{array}{l}\text { No difference found in plasma/CSF Se } \\
\text { ratio between AD patients and } \\
\text { controls. }\end{array}$ & $\begin{array}{l}\text { Gerhardsson et al. } 2011 \\
\text { [141] }\end{array}$ \\
\hline $\begin{array}{l}\text { PREADViSE recruited } 7540 \text { men } \\
\text { mean age } 67.5 \text { (5.3) y to an RCT } \\
\text { of Se, or vitamin E, or both, or } \\
\text { placebo. After } 7 \mathrm{y} \text {, the trial was } \\
\text { converted to cohort study; } 3786 \\
\text { men continued into the cohort } \\
\text { study. Dementia cases were } \\
\text { identified. }\end{array}$ & $\begin{array}{l}\text { Four treatment groups: Se } \\
(200 \mu \mathrm{g} / \mathrm{d}) \text {, or vitamin } \mathrm{E}(400 \\
\mathrm{IU} / \mathrm{d}) \text {, or both, or placebo. No } \\
\text { measurement of Se status. }\end{array}$ & $\begin{array}{l}\text { Not disclosed. However, } \\
\text { baseline serum Se } \\
\text { concentration in the } \\
\text { parent SELECT study } \\
\text { was } 135 \mu \mathrm{g} / \mathrm{L} \text { [142] }\end{array}$ & $\begin{array}{l}\text { No positive effect of Se on the } \\
\text { development of dementia. The } \\
\text { intervention was stopped along with } \\
\text { the parent trial, but the study } \\
\text { continued as observational. Dementia } \\
\text { incidence }(4.4 \%) \text { did not differ } \\
\text { between the study arms: HR ( } 95 \% \mathrm{CI}) \\
0.88(0.64-1.20) \text { for vitamin E, } 0.83 \\
(0.60-1.13) \text { for Se, and } 1.00 \\
(0.75-1.35) \text { for the combination, } v \text { s. } \\
\text { placebo. }\end{array}$ & Kryscio et al. 2017 [143] \\
\hline
\end{tabular}

the indirect relation of SELENOP with cytoskeleton via Se delivery to the cells seems more likely. According to Du et al., the association of SELENOP and $\alpha$-tubulin might imply that SELENOP has a role in regulating the dynamics of microtubules; this is crucial for intracellular transport and the maintenance of cell polarity [72].

We hypothesize that the interaction between SELENOP and $\alpha$-tubulin may contribute to $\mathrm{AD}$ pathology, affecting tau-protein phosphorylation and the formation of neurofibrillary tangles. The in vitro studies discussed in this section need to be supported by in vivo and human-based experiments which are lacking at present.

\section{In vivo and ex vivo studies}

Most of the evidence implicating SELENOP in neurodegeneration pathology and etiology is based upon murine transgenic studies. Selenop is one of three murine selenoprotein genes, which along with GPX4 and selenoprotein W (SELENOW), has a high level of expression in over $90 \%$ of murine brain regions, including the olfactory area, 
hippocampus, isocortex, and cerebellar cortex [108]. Interestingly, GPX4, the only GPX form required for proper embryogenesis [82], was recently reported to require $\mathrm{Se}$, as $\mathrm{Sec}$, specifically for postnatal development, preventing fatal epileptic seizures [83]. At the same time, the activity of mutant Cys-GPX4 is sufficient for the normal embryonic development [83].

All mice brain regions have been shown to be highly dependent on SELENOP for maintenance of the Se level in the brain [109]; knockout of ApoER2 or Selenop, along with neuron-specific ablation of selenoprotein biosynthesis, caused neurological dysfunction [54,62,110,111]. Within 12 days, Selenop-knockout mice (Selenop ${ }^{-/}$), fed with a Se-deficient diet showed degeneration in the majority of brain regions [111]. Importantly, the brainstem and thalamus suffered most from SELENOP depletion, resulting in impaired motor function [110]. Additionally, neuronal loss was observed in the somatosensory cortex and lateral striatum [111], while there was significant impairment in hippocampus-dependent learning [112]. The observed effects were attributed to the neuronal and axonal loss and changes in the morphology of hippocampal cells [111]. Increasing brain Se by raising Se intake reduced the degeneration [23,113]. $\gamma$-aminobutyric acidergic (GABAergic) parvalbumin-positive interneurons appear to be the most susceptible to SELENOP deletion [114]. These neurons participate in neural activity synchronization and have already been shown to be highly sensitive to oxidative damage [115-117]. The degeneration of these parvalbumin-positive interneurons seems to be the reason for the epileptiform phenotype in Selenop ${ }^{-/}$animals [118]. ApoER2-mediated uptake of SELENOP (Fig. 2) appears to be a major neuroprotective mechanism for these neurons $[13,114]$. Finally, a comparison study of brain selenoprotein expression in the wild-type and Selenop-knockout mice showed considerably reduced expression of GPX4, selenoproteins $\mathrm{K}, \mathrm{M}, \mathrm{W}$, and other selenoproteins in the latter [119]. Thus, it may be concluded that the deletion of SELENOP, and presumably Se deficiency, induce neuronal and axonal degeneration in addition to neuronal changes in the developing human brain [111], resulting in motor dysfunction and behavioral phenotype $[110,112]$. On the other hand, a Serich diet improves the state of both Selenop-knockouts [113] and epileptic patients $[120,121]$, so there must be routes of Se delivery to the CNS, independent of SELENOP-mediated uptake.

Astrocytes, which are less sensitive than neurons to oxidative stress [122], increase the production of antioxidant selenoproteins upon brain injury [54]. The hypothesis, derived from the observations reviewed here, is that SELENOP has a protective role in the brain. Finally, another possible effect of Se and selenoproteins on the neurodegenerative processes may be related to their immunological activity. Inflammation is involved in AD pathology [123], and Se is known to affect NF- $\mathrm{KB}$ and AP-1 associated pathways [124,125].

\section{Human studies linking Se exposure or supplementation to neurodegeneration}

Since the central hypothesis that SELENOP has a role in AD and, more generally, in brain disorders, is linked to the delivery of Se to brain tissue for selenoprotein synthesis, we will examine the epidemiological evidence linking Se exposure/supplementation to neurodegeneration $[6,15,34,126,127]$. Observational epidemiological studies have shown that higher Se status benefits neurological function and cognitive performance. In the French EVA cohort of 1166 people aged 60-70 years [128], a significantly elevated risk of cognitive decline was observed in those with low plasma Se (Table 1) at baseline [129], though other studies reported the absence of such an association [130]. Additionally, cognitive function correlated with the degree of decrease in plasma-Se concentration over a nine-year period [131]. A crosssectional study (2003-2005) of 2000 adults ( $\geq 65 \mathrm{y}$ ) from four rural sites in two provinces of China, reported a strong association between nail Se concentration (Table 1) and performance in cognitive tests [132]. This is in agreement with the findings of a set of small studies by
Cardoso et al. [133-135], who reported (i) lower levels of plasma and erythrocyte Se concentrations in patients with $\mathrm{AD}$ and MCI, (ii) decreased levels of Se in plasma and erythrocytes of $\mathrm{AD}$ patients vs. matched controls from São Paulo, Brazil and, (iii) a decreased concentration $(\mathrm{p}<0.05)$ of $\mathrm{Se}$ in erythrocytes of $\mathrm{AD}$ patients than in healthy controls (28 cases $v s .29$ controls) [135], though no difference was observed for total Se in serum or CSF. It needs to be mentioned that in the context of cognitive function in older adults, low plasma Se may result from reduced production of secreted GPX3 and particularly of SELENOP caused by inflammatory cytokines during the acute-phase response [136]. On the other hand, systemic inflammation in AD patients $[97,137]$ may cause decreased circulating Se concentration. Correspondingly, a state of chronic inflammation was shown to cause decreased Se status $[138,139]$. It is worth mentioning, though, that improved cognition in the elderly and $\mathrm{AD}$ should probably not be considered as direct opposites, since the age-associated decline in cognition lacks the characteristic pathologic events present in AD. This should be considered when evaluating the results of EVA [131] and similar studies [132]. As for the small studies of Cardoso et al. [133-135], these may lack statistical power to be conclusive.

Gerhardsson et al. [140] reported altered Se levels in blood plasma of patients with $\mathrm{AD}$, but a later study by the same research group showed no difference in Se CSF/blood plasma ratios between AD patients and healthy controls [141]. Additionally, in Indian cohorts of AD and vascular-dementia patients, blood Se was no different than in sexand age-matched controls [144]. Furthermore, blood Se did not correlate with the activity of GPX, thioredoxin reductase, plasma A $\beta 42$, plasma tau and tau-to-A $\beta 42$ ratio. Interestingly, human genetic studies also point to the protective role of selenoproteins, showing that mutations in Sec synthesis machinery cause progressive cerebellocerebral atrophy (PCCA) neurological impairment. The phenotype, which comprises non-dysmorphic, profound mental retardation is often accompanied by myoclonic or generalized tonic-clonic seizures [125,145]. Importantly, PCCA syndrome somewhat resembles the Selenopknockout phenotype of transgenic animals [146]. SELENOP-deficient mice develop hyperexcitability and seizures [147], similar to childhood epilepsy patients who are Se deficient $[148,149]$.

Nevertheless, some observational studies considered certain Se species as potential risk factors for neurodegeneration. Vinceti et al. reported that higher levels of SELENOP in CSF were associated with a lower risk of sporadic amyotrophic lateral sclerosis (ALS), while a higher risk of neurodegeneration was associated with elevated selenite in CSF [35]. A further cohort study including ALS patients with diseaseassociated mutations (C9ORF72, SOD1, FUS, TARDBP, ATXN2, and TUBA4A) has reported elevated levels of inorganic Se (selenite and selenate), GPX and SELENOP in a patient with the tubulin-related TUBA4A mutation, whereas in the remaining ALS individuals, elevated selenomethionine was observed [36]. Finally, in a recently published study, the increased risk (adjusted hazard ratio of 3.1, 95\% confidence interval 1.0-9.5) of developing AD later in life was observed in MCI patients with increased concentration of the potentially toxic inorganic selenium species, selenate, Se(VI), in CSF [150]. The study was conducted in $56 \mathrm{MCI}$ patients; the development of $\mathrm{AD}$ was monitored after a median follow-up of 42 months.

Notably, a 2011 meta-analysis of observational studies, cohort studies and placebo-controlled trials investigating the association between cognitive decline and Se supplementation found no evidence for a role of Se in the treatment of $\mathrm{AD}$ [15]. Table 1 presents the studies that were not included in the meta-analysis.

The most recent placebo-controlled, randomized clinical trial (RCT), PREADVISE, that ended in 2015 showed no effect of Se supplementation on AD risk in elderly males [143]. This extensive study (7540 participants, mean age 67, 2002-2015) was run as an ancillary study of the Selenium and Vitamin E Cancer Prevention Trial (SELECT) [142]. When the SELECT was stopped in 2009 owing to an interim analysis that showed a lack of a beneficial effect on prostate cancer [142], 


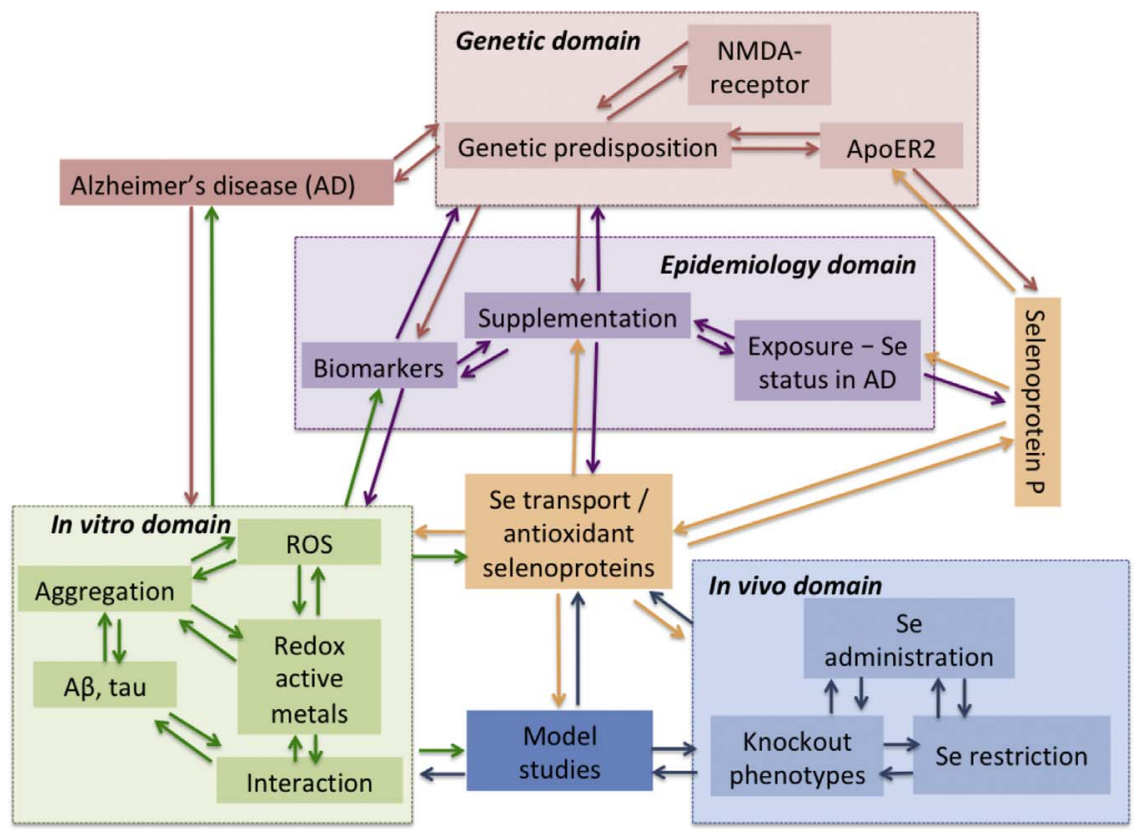

Fig. 3. A summary of the findings on SELENOP in AD. The scheme illustrates the body of research connecting studies on $\mathrm{AD}$ and selenium with a focus on SELENOP. The smaller boxes indicate the primary processes or components of interest in the studies performed. Larger boxes summarize relevant domains genetic, epidemiology, in vitro, and in vivo studies. The arrows demonstrate the interactions within and between the domains, leading to new hypotheses and study designs.
PREADVISE was continued as a cohort study [151]. PREADVISE showed a lack of effect of both Se and vitamin E on dementia riskadjusted hazard ratios $(95 \% \mathrm{CI})$, were $0.83(0.60-1.13), 0.88$ (0.64-1.20) and $1.00(0.75-1.35)$ for selenium, vitamin E, and (selenium + vitamin E), respectively. However, the lack of effect of Se supplementation in the PREADVISE cohort is hardly surprising [152-154], given the high baseline Se status of the participants in the parent SELECT, where baseline serum Se concentration was $136 \mu \mathrm{g} / \mathrm{L}$ [142]. At such a baseline serum Se concentration, SELENOP, and probably all selenoproteins would already have attained a plateau of concentration or activity, precluding any further benefit from additional Se [155].

A role of Se in seizures, coordination, and Parkinson's disease (PD) [126] has been investigated in a number of studies. The InChianti study of coordination performance in elderly participants $(n=1012$, age $\geq 65 \mathrm{y}$ ) found poorer performance-based coordination results in individuals with lower plasma Se than in those with higher concentrations, though the authors reported no association with PD morbidity, rigidity, rest-tremor, or the number of postural abnormalities [156]. However, the investigators noted a significant trend towards increased prevalence of PD in the lower Se quartiles. Other studies have reported significantly lower serum Se concentration in children and adults with epileptic seizures [120] and in children with febrile seizures [157].

Although a number of human studies have addressed the possible role of Se supplementation in preventing cognitive decline or $\mathrm{AD}$, the data are still inconclusive. The reason for inconsistencies between different studies may be related to confounding bias, differences in evaluation of dementia and cognitive performance, inadequate controls, unspecified initial Se status and speciation, so only a fraction of the studies may be described as 'high quality' [34,158].

\section{Potential mechanisms for the effect of SELENOP in Alzheimer's disease}

The ApoE- $\varepsilon 4$ allele is a well-known genetic risk factor for the lateonset sporadic AD in most populations [159]. The mechanism by which $A p o E-\varepsilon 4$ increases the risk of $\mathrm{AD}$ is still to be characterized. For other alleles of ApoE, ApoE- $\varepsilon 3$ and in particular ApoE- $\varepsilon 2$, there is an enhanced proteolytic breakdown of $\mathrm{A} \beta$, both intra- and extracellularly, so the increased vulnerability to the AD pathologic changes may be attributed to relative ineffectiveness of the ApoE- $\varepsilon 4$ isoform to inhibit amyloidogenesis. It is therefore of considerable interest that the ApoER2 is responsible for uptake of Se, as SELENOP, in neurons. Thus, SELENOP may have a crucial neuroprotective role that prevents apoptosis and increases neuronal survival by mitigating the $\mathrm{A} \beta$-induced oxidative challenge [60].

The expression of SELENOP in postmortem brains from patients with confirmed $\mathrm{AD}$ pathology and control tissue from healthy individuals was compared [41]. It was found that SELENOP immunoreactivity colocalized with $\mathrm{A} \beta$ plaques and neurofibrillary tangles $[107,160]$. Other non-diffuse and dense-core $A \beta$ lesions were frequently associated with SELENOP immunopositive cells. A significant association between $\mathrm{A} \beta$ plaques and SELENOP, along with multiple cells immunoreactive to SELENOP, was observed. Bellinger et al. [107] showed a strong link between SELENOP and hallmarks of $\mathrm{AD}$ (A $\beta$ plaques and neurofibrillary tangles). These postmortem studies additionally indicate the intracellular presence of SELENOP, which is confirmed by other studies [43]. SELENOP up-regulation may relate to its antioxidant properties or increased Se requirement in AD neuronal tissue. Moreover, SELENOP binding to $\mathrm{A} \beta$ and neurofibrillary tangles may sequester Se, reducing Se supply to neurons and glial cells, thereby promoting oxidative stress. This is in agreement with the in vitro data of Takemoto et al. [60], who reported higher $\mathrm{A} \beta$ toxicity in Selenop-knockout mice neuroblastoma cells than in wild-type cells.

In a recent study, the $\mathrm{AD}$ brain was shown to increase the release of SELENOP from the choroid plexus to the CSF [160]. Rueli et al. [160] related the increase in expression of SELENOP in the choroid plexus and its increased secretion to excessive reactive oxygen species, cellular stress, and inflammation, caused by $\mathrm{AD}$ changes in the brain. Postmortem studies by Bellinger et al. $[61,81]$ in the PD brain also showed altered GPX4 and SELENOP expression. SELENOP was reduced in the substantia nigra of PD brains but with a relative increase compared to the total number of nigral cells. Importantly, SELENOP localized in Lewy bodies, i.e. the PD brain lesions [61]. These findings may be attributed to the compensatory response in SELENOP expression towards oxidative stress associated with neurodegeneration. However, some additional mechanisms may be involved; for instance, the studies in postmortem PD brains showed that SELENOP presumably had its signaling function in the dopaminergic synapses through direct interaction with ApoER2 [61]. Research has shown that ApoER2, which is known to have postsynaptic localization [161], is associated with glutamatergic N-methyl-D-aspartate (NMDA) receptors [162], which are 
probably involved in AD pathology. These observations suggest that there may be some form of interaction between SELENOP and $A \beta$, leading to complex formation. It should be emphasized though, that increased expression of SELENOP and its presence within AD brain lesions does not necessarily imply a positive effect against AD progression [163]. Elevated SELENOP may be just a bystander associated with redox stress or may take part in the detrimental processes in the $\mathrm{AD}$ brain. This issue demands further exploration. Additionally, since SELENOP is mainly an extracellular protein, the results of certain in vitro studies on SELENOP interaction with intracellularly localized proteins (e.g. $\alpha$-tubulin, tau-protein etc.) and even on interaction with $\mathrm{A} \beta$ and metal ions should be treated with caution since they may not occur in the real brain environment at actual concentrations of SELENOP and its counterparts. Finally, the results of postmortem studies may be biased by tissue decay, lifetime drug treatment, and/or tissue preparation.

In accordance with the metal dysregulation hypothesis, it is tempting to consider that $\mathrm{AD}$ treatment or prevention strategies might include optimizing Se intake [127]. The selenoprotein family is crucial for normal brain function, and SELENOP is among the selenoproteins of importance. Fig. 3 summarizes current knowledge of the role of SELENOP in AD. In our opinion, further studies should more directly address the issue of optimal Se supply, relevant biomarkers of Se status and optimal reference ranges [126]. For instance, some authors consider plasma/serum or nail Se as mainly Se exposure markers, not reflecting the body's selenoprotein machinery and Se speciation in general [158]. Aside from purely analytical complications related to the measurement itself, the activity or concentration of SELENOP and GPX3 are also being questioned as relevant markers, since in this case the terms 'optimal' or 'optimized' expression/activity [164] is often substituted by 'maximal' or 'maximized' [163], which is probably not appropriate for all populations and health conditions. Although the issue of markers and optimal intake range has been discussed since the early days of selenobiology, they seem unclear even today and probably depend on the health effect being discussed.

\section{Conclusion and perspectives}

SELENOP, as a central selenoprotein underpinning body Se hierarchy and brain Se homeostasis, has an important role in the body. Research shows that SELENOP affects $\mathrm{A} \beta$ and hyperphosphorylated tau aggregation and toxicity in addition to interacting with redox-active metals in the brain, such as $\mathrm{Cu}, \mathrm{Fe}$, and Hg. It is capable of antioxidant enzyme activity and appears to possess signaling functions via neuronal ApoER2. As the Se-transport protein, it provides Se to neurons and glial cells to synthesize antioxidant selenoproteins that mediate the redoxstress response. Nevertheless, certain roles of SELENOP in brain function still require clarification, e.g., its involvement in glial activation, and its relation to certain 'healthy' and pathological signaling pathways in neuronal and glial tissue, including its roles in neuronal calcium homeostasis/excitotoxicity.

Human studies need to pay more attention to Se status; there is no rationale for giving supplemental Se to population groups where Se status is already adequate and SELENOP concentration, and probably that of other selenoproteins, has reached its maximum. Indeed, this was the case in the only large randomized, controlled trial to date (PREADViSE) that attempted to investigate the effect of Se supplementation on $\mathrm{AD}$ risk in elderly males and, unsurprisingly, found no effect [143]. Symptoms of Se toxicity (alopecia and dermatitis) were in fact shown in SELECT, the parent study of PREADViSE [142], suggesting that the dose that was given had adverse effects in this population that already had quite a high Se status. Hence this outcome is not relevant to Se-deficient populations. It needs to be appreciated that the relationship between Se intake and status is not linear, but approximates more closely to a U-shape where adverse effects (e.g. on mortality and prostate cancer) are found both at low and high Se intake/ status [4,165-167]. The majority of neurological studies to date point to a neuroprotective effect of SELENOP against cognitive decline and, possibly, AD. Any further RCTs in this domain, if carried out in populations of appropriately low Se status (e.g. in European populations) may lead to novel strategies for treatment and prevention of dementia.

\section{Acknowledgements}

We thank Dr. Marco Vinceti for valuable comments, which helped us to increase the quality of this paper. Nikolay Solovyev acknowledges the funding from the Russian Foundation for Basic Research (grant No. 16-33-60004 mol_a_dk). Yaroslav Dubrovskii thanks the St. Petersburg State University for personal funding.

\section{Declaration of interest}

None.

\section{References}

[1] V.N. Gladyshev, E.S. Arnér, M.J. Berry, R. Brigelius-Flohée, E.A. Bruford, R.F. Burk, B.A. Carlson, S. Castellano, L. Chavatte, M. Conrad, P.R. Copeland, A.M. Diamond, D.M. Driscoll, A. Ferreiro, L. Flohé, F.R. Green, R. Guigó, D.E. Handy, D.L. Hatfield, J. Hesketh, P.R. Hoffmann, A. Holmgren, R.J. Hondal, M.T. Howard, K. Huang, H.Y. Kim, I.Y. Kim, J. Köhrle, A. Krol, G.V. Kryukov, B.J. Lee, B.C. Lee, X.G. Lei, Q. Liu, A. Lescure, A.V. Lobanov, J. Loscalzo, M. Maiorino, M. Mariotti, K.S. Prabhu, M.P. Rayman, S. Rozovsky, G. Salinas, E.E. Schmidt, L. Schomburg, U. Schweizer, M. Simonović, R.A. Sunde, P.A. Tsuji, S. Tweedie, F.F. Ursini, P.D. Whanger, Y. Zhang, Selenoprotein gene nomenclature, J. Biol. Chem. 291 (2016) 24036-24040.

[2] G.V. Kryukov, S. Castellano, S.V. Novoselov, A.V. Lobanov, O. Zehtab, R. Guigo, V.N. Gladyshev, Characterization of mammalian selenoproteomes, Science 300 (2003) 1439-1443.

[3] J. Chen, M.J. Berry, Selenium and selenoproteins in the brain and brain diseases, J. Neurochem. 86 (2004) 1-12.

[4] M.P. Rayman, Selenium and human health, Lancet 379 (2012) 1256-1268.

[5] A.V. Lobanov, D.L. Hatfield, V.N. Gladyshev, Eukaryotic selenoproteins and selenoproteomes, BBA-Gen. Subj. 1790 (2009) 1424-1428.

[6] M. Vinceti, J. Mandrioli, P. Borella, B. Michalke, A. Tsatsakis, Y. Finkelstein, Selenium neurotoxicity in humans: bridging laboratory and epidemiologic studies, Toxicol. Lett. 230 (2014) 295-303.

[7] B. Michalke, D. Willkommen, E. Drobyshev, N. Solovyev, The importance of speciation analysis in neurodegeneration research (in press), TRAC-Trend Anal. Chem. (2017), http://dx.doi.org/10.1016/j.trac.2017.08.008.

[8] H. Steinbrenner, R. Brigelius-Flohé, Das essenzielle Spurenelement Selen: Selenbedarf in Gesundheit und Krankheit, Aktuel Ernahr. 40 (2015) 368-378.

[9] M. Kuhbacher, J. Bartel, B. Hoppe, D. Alber, G. Bukalis, A.U. Brauer, D. Behne, A. Kyriakopoulos, The brain selenoproteome: priorities in the hierarchy and different levels of selenium homeostasis in the brain of selenium-deficient rats, J. Neurochem. 110 (2009) 133-142.

[10] R.F. Burk, K.E. Hill, A.K. Motley, Selenoprotein metabolism and function: Evidence for more than one function for selenoprotein P, J. Nutr. 133 (2003) 1517S-1520S

[11] R.F. Burk, K.E. Hill, R. Read, T. Bellew, Response of rat selenoprotein P to selenium administration and fate of its selenium, Am. J. Physiol.-Endocrinol. Metabol. 261 (1991) E26-E30.

[12] R.F. Burk, K.E. Hill, Selenoprotein P-expression, functions, and roles in mammals, BBA-Gen. Subj. 1790 (2009) 1441-1447.

[13] N.D. Solovyev, Importance of selenium and selenoprotein for brain function: from antioxidant protection to neuronal signalling, J. Inorg. Biochem. 153 (2015) 1-12.

[14] E. Ozdemir, Physiopathological role of selenium and selenoprotein in neuropsychiatry disease, J. Med. Sci. 11 (2011) 11-18.

[15] M. Loef, G.N. Schrauzer, H. Walach, Selenium and Alzheimer's disease: a systematic review, J. Alzheimers Dis. 26 (2011) 81-104.

[16] B.R. Cardoso, B.R. Roberts, A.I. Bush, D.J. Hare, Selenium, selenoproteins and neurodegenerative diseases, Metallomics 7 (2015) 1213-1228.

[17] A.A. Turanov, R.A. Everley, S. Hybsier, K. Renko, L. Schomburg, S.P. Gygi, D.L. Hatfield, V.N. Gladyshev, Regulation of Selenocysteine Content of Human Selenoprotein P by Dietary Selenium and Insertion of Cysteine in Place of Selenocysteine, PLoS One 10 (2015) e0140353.

[18] Y. Xia, K.E. Hill, D.W. Byrne, J. Xu, R.F. Burk, Effectiveness of selenium supplements in a low-selenium area of China, Am. J. Clin. Nutr. 81 (2005) 829-834.

[19] L.V. Papp, J. Lu, A. Holmgren, K.K. Khanna, From selenium to selenoproteins: synthesis, identity, and their role in human health, Antioxid. Redox Signal. 9 (2007) 775-806.

[20] S. Dato, F. De Rango, P. Crocco, G. Passarino, G. Rose, Antioxidants and quality of aging: further evidences for a major role of TXNRD1 gene variability on physical performance at old age, Oxid. Med. Cell Longev. 2015 (2015) 926067.

[21] M.P. Rayman, Food-chain selenium and human health: emphasis on intake, Br. J. Nutr. 100 (2008) 254-268.

[22] C.M. Weekley, H.H. Harris, Which form is that? The importance of selenium 
speciation and metabolism in the prevention and treatment of disease, Chem. Soc. Rev. 42 (2013) 8870-8894.

[23] R.F. Burk, K.E. Hill, G.E. Olson, E.J. Weeber, A.K. Motley, V.P. Winfrey, L.M. Austin, Deletion of apolipoprotein E receptor-2 in mice lowers brain selenium and causes severe neurological dysfunction and death when a low-selenium diet is fed, J. Neurosci. 27 (2007) 6207-6211.

[24] G.E. Olson, V.P. Winfrey, S.K. NagDas, K.E. Hill, R.F. Burk, Apolipoprotein E receptor-2 (ApoER2) mediates selenium uptake from selenoprotein P by the mouse testis, J. Biol. Chem. 282 (2007) 12290-12297.

[25] D.J. Selkoe, Folding proteins in fatal ways, Nature 426 (2003) 900-904.

[26] H. Kozlowski, M. Luczkowski, M. Remelli, D. Valensin, Copper, zinc and iron in neurodegenerative diseases (Alzheimer's, Parkinson's and prion diseases), Coord. Chem. Rev. 256 (2012) 2129-2141.

[27] M. Valko, D. Leibfritz, J. Moncol, M.T.D. Cronin, M. Mazur, J. Telser, Free radicals and antioxidants in normal physiological functions and human disease, Int. J. Biochem. Cell B 39 (2007) 44-84.

[28] H.W. Querfurth, F.M. LaFerla, Alzheimer's disease, N. Engl. J. Med. 362 (2010) 329-344.

[29] G.T. Sutherland, B. Chami, P. Youssef, P.K. Witting, Oxidative stress in Alzheimer's disease: primary villain or physiological by-product? Redox Rep. 18 (2013) 134-141.

[30] T. Lu, Y. Pan, S.Y. Kao, C. Li, I. Kohane, J. Chan, B.A. Yankner, Gene regulation and DNA damage in the ageing human brain, Nature 429 (2004) 883-891.

[31] J.A. Miller, M.C. Oldham, D.H. Geschwind, A systems level analysis of transcriptional changes in Alzheimer's disease and normal aging, J. Neurosci. 28 (2008) 1410-1420.

[32] J.F. Munoz-Gutierrez, S.A. Pierle, D.A. Schneider, T.V. Baszler, J.B. Stanton, Transcriptomic determinants of scrapie prion propagation in cultured ovine microglia, PLoS One 11 (2016) e0147727.

[33] W.J. Strittmatter, A.M. Saunders, D. Schmechel, M. Pericakvance, J. Enghild, G.S. Salvesen, A.D. Roses, Apolipoprotein-E - high-avidity binding to beta-amyloid and increased frequency of type-4 allele in late-onset familial Alzheimer-disease, Proc. Natl. Acad. Sci. USA 90 (1993) 1977-1981.

[34] L.O. Killin, J.M. Starr, I.J. Shiue, T.C. Russ, Environmental risk factors for dementia: a systematic review, BMC Geriatr. 16 (2016) 175.

[35] M. Vinceti, N. Solovyev, J. Mandrioli, C.M. Crespi, F. Bonvicini, E. Arcolin, E. Georgoulopoulou, B. Michalke, Cerebrospinal fluid of newly diagnosed amyotrophic lateral sclerosis patients exhibits abnormal levels of selenium species including elevated selenite, Neurotoxicology 38 (2013) 25-32.

[36] J. Mandrioli, B. Michalke, N. Solovyev, P. Grill, F. Violi, C. Lunetta, A. Conte V.A. Sansone, M. Sabatelli, M. Vinceti, Elevated levels of selenium species in cerebrospinal fluid of amyotrophic lateral sclerosis patients with disease-associated gene mutations, Neurodegener. Dis. 17 (2017) 171-180.

[37] H. Misu, T. Takamura, H. Takayama, H. Hayashi, N. Matsuzawa-Nagata, S. Kurita, K. Ishikura, H. Ando, Y. Takeshita, T. Ota, M. Sakurai, T. Yamashita, E. Mizukoshi, T. Yamashita, M. Honda, K. Miyamoto, T. Kubota, N. Kubota, T. Kadowaki, H.J. Kim, I.K. Lee, Y. Minokoshi, Y. Saito, K. Takahashi, Y. Yamada, N. Takakura, S. Kaneko, A liver-derived secretory protein, selenoprotein P, causes insulin resistance, Cell Metab. 12 (2010) 483-495.

[38] H. Sies, Role of metabolic $\mathrm{H}_{2} \mathrm{O} 2$ generation: redox signaling and oxidative stress, J. Biol. Chem. 289 (2014) 8735-8741.

[39] H. Takayama, H. Misu, H. Iwama, K. Chikamoto, Y. Saito, K. Murao, A. Teraguchi, F. Lan, A. Kikuchi, R. Saito, N. Tajima, T. Shirasaki, S. Matsugo, K.-i. Miyamoto, S. Kaneko, T. Takamura, Metformin suppresses expression of the selenoprotein P gene via an AMP-activated Kinase (AMPK)/ $\mathrm{FoxO}_{3}$ a pathway in H4IIEC3 hepatocytes, J. Biol. Chem. 289 (2014) 335-345.

[40] X.G. Yang, K.E. Hill, M.J. Maguire, R.F. Burk, Synthesis and secretion of selenoprotein P by cultured rat astrocytes, BBA-Gen. Subj. 1474 (2000) 390-396.

[41] R. Pillai, J.H. Uyehara-Lock, F.P. Bellinger, Selenium and selenoprotein function in brain disorders, IUBMB Life 66 (2014) 229-239.

[42] K.E. Hill, S. Wu, A.K. Motley, T.D. Stevenson, V.P. Winfrey, M.R. Capecchi, J.F. Atkins, R.F. Burk, Production of Selenoprotein P (Sepp1) by hepatocytes is central to selenium homeostasis, J. Biol. Chem. 287 (2012) 40414-40424.

[43] M. Scharpf, U. Schweizer, T. Arzberger, W. Roggendorf, L. Schomburg, J. Kohrle, Neuronal and ependymal expression of selenoprotein P in the human brain, J. Neural Transm. 114 (2007) 877-884.

[44] M. Koga, H. Tanaka, K. Yomogida, J. Tsuchida, K. Uchida, M. Kitamura, S. Sakoda, K. Matsumiya, A. Okuyama, Y. Nishimune, Expression of Selenoprotein-P messenger ribonucleic acid in the rat testis, Biol. Reprod. 58 (1998) 261-265.

[45] Y. Zhang, X. Chen, Reducing selenoprotein P expression suppresses adipocyte differentiation as a result of increased preadipocyte inflammation, Am. J. Physiol. - Endocrinol. Metab. 300 (2011) E77-E85.

[46] H. Steinbrenner, A.-L. Hotze, B. Speckmann, A. Pinto, H. Sies, M. Schott, M. Ehlers, W.A. Scherbaum, S. Schinner, Localization and regulation of pancreatic selenoprotein P, J. Mol. Endocrinol. 50 (2013) 31-42.

[47] N. Solovyev, A. Berthele, B. Michalke, Selenium speciation in paired serum and cerebrospinal fluid samples, Anal. Bioanal. Chem. 405 (2013) 1875-1884.

[48] H. Steinbrenner, L. Alili, E. Bilgic, H. Sies, P. Brenneisen, Involvement of selenoprotein $\mathrm{P}$ in protection of human astrocytes from oxidative damage, Free Radic. Biol. Med. 40 (2006) 1513-1523.

[49] R.F. Burk, K.E. Hill, Regulation of selenium metabolism and transport, Annu. Rev. Nutr. 35 (2015) 109-134.

[50] L.V. Papp, A. Holmgren, K.K. Khanna, Selenium and selenoproteins in health and disease, Antioxid. Redox Signal. 12 (2010) 793-795.

[51] L.V. Papp, J.N. Wang, D. Kennedy, D. Boucher, Y. Zhang, V.N. Gladyshev, R.N. Singh, K.K. Khanna, Functional characterization of alternatively spliced human SECISBP2 transcript variants, Nucleic Acids Res. 36 (2008) 7192-7206.

[52] L. Qiong, J. Liang, T. Jing, N. Jiazwan, The molecular biology of selenoproteins and their effects on diseases, Prog. Chem. 21 (2009) 819-830.

[53] S.V. Novoselov, H.Y. Kim, D. Hua, B.C. Lee, C.M. Astle, D.E. Harrison, B. Friguet, M.E. Moustafa, B.A. Carlson, D.L. Hatfield, V.N. Gladyshev, Regulation of selenoproteins and methionine sulfoxide reductases A and B1 by age, calorie restriction, and dietary selenium in mice, Antioxid. Redox Signal. 12 (2010) 829-838.

[54] H. Steinbrenner, H. Sies, Selenium homeostasis and antioxidant selenoproteins in brain: implications for disorders in the central nervous system, Arch. Biochem. Biophys. 536 (2013) 152-157.

[55] R. Brigelius-Flohe, L. Flohe, Selenium and redox signaling, Arch. Biochem. Biophys. 617 (2017) 48-59.

[56] Y. Ogra, Y. Anan, Selenometabolomics: identification of selenometabolites and specification of their biological significance by complementary use of elemental and molecular mass spectrometry, J. Anal. At. Spectrom. 24 (2009) 1477-1488.

[57] R.F. Burk, G.E. Olson, K.E. Hill, V.P. Winfrey, A.K. Motley, S. Kurokawa, Maternalfetal transfer of selenium in the mouse, FASEB J. 27 (2013) 3249-3256.

[58] S. Kurokawa, K.E. Hill, W.H. McDonald, R.F. Burk, Long isoform mouse Selenoprotein P (Sepp1) supplies rat myoblast L8 cells with selenium via endocytosis mediated by heparin binding properties and Apolipoprotein E Receptor2 (ApoER2), J. Biol. Chem. 287 (2012) 28717-28726.

[59] U. Schweizer, A.U. Brauer, J. Kohrle, R. Nitsch, N.E. Savaskan, Selenium and brain function: a poorly recognized liaison, Brain Res Brain Res Rev. 45 (2004) 164-178.

[60] A.S. Takemoto, M.J. Berry, F.P. Bellinger, Role of selenoprotein P in Alzheimer's disease, Ethn. Dis. 20 (2010) 92-95.

[61] F.P. Bellinger, A.V. Raman, R.H. Rueli, M.T. Bellinger, A.S. Dewing, L.A. Seale, M.A. Andres, J.H. Uyehara-Lock, L.R. White, G.W. Ross, M.J. Berry, Changes in selenoprotein P in substantia nigra and putamen in Parkinson's disease, J. Park. Dis. 2 (2012) 115-126.

[62] A.V. Raman, M.W. Pitts, A. Seyedali, A.C. Hashimoto, L.A. Seale, F.P. Bellinger, M.J. Berry, Absence of selenoprotein P but not selenocysteine lyase results in severe neurological dysfunction, Genes Brain Behav. 11 (2012) 601-613.

[63] J.C. Whitin, S. Bhamre, D.M. Tham, H.J. Cohen, Extracellular glutathione peroxidase is secreted basolaterally by human renal proximal tubule cells, Am. J. Physiol.-Ren. 283 (2002) F20-F28.

[64] G.E. Olson, V.P. Winfrey, K.E. Hill, R.F. Burk, Megalin mediates Selenoprotein P uptake by kidney proximal tubule epithelial cells, J. Biol. Chem. 283 (2008) 6854-6860.

[65] M.A. Pericak-Vance, J.L. Bebout, P.C. Gaskell Jr, L.H. Yamaoka, W.Y. Hung, M.J. Alberts, A.P. Walker, R.J. Bartlett, C.A. Haynes, K.A. Welsh, N.L. Earl, A. Heyman, C.M. Clark, A.D. Roses, Linkage studies in familial Alzheimer disease: evidence for chromosome 19 linkage, Am. J. Hum. Genet 48 (1991) 1034-1050.

[66] J. van Eersel, Y.D. Ke, X. Liu, F. Delerue, J.J. Kril, J. Gotz, L.M. Ittner, Sodium selenate mitigates tau pathology, neurodegeneration, and functional deficits in Alzheimer's disease models, Proc. Natl. Acad. Sci. USA 107 (2010) 13888-13893.

[67] N.M. Corcoran, D. Martin, B. Hutter-Paier, M. Windisch, T. Nguyen, L. Nheu, L.E. Sundstrom, A.J. Costello, C.M. Hovens, Sodium selenate specifically activates PP2A phosphatase, dephosphorylates tau and reverses memory deficits in an Alzheimer's disease model, J. Clin. Neurosci. 17 (2010) 1025-1033.

[68] N.C. Jones, T. Nguyen, N.M. Corcoran, D. Velakoulis, T. Chen, R. Grundy, T.J. O'Brien, C.M. Hovens, Targeting hyperphosphorylated tau with sodium selenate suppresses seizures in rodent models, Neurobiol. Dis. 45 (2012) 897-901.

[69] G. Song, Z. Zhang, L. Wen, C. Chen, Q. Shi, Y. Zhang, J. Ni, Q. Liu, Selenomethionine ameliorates cognitive decline, reduces tau hyperphosphorylation, and reverses synaptic deficit in the triple transgenic mouse model of Alzheimer's disease, J. Alzheimers Dis. 41 (2014) 85-99.

[70] C. Ballatore, V.M.Y. Lee, J.Q. Trojanowski, Tau-mediated neurodegeneration in Alzheimer's disease and related disorders, Nat. Rev. Neurosci. 8 (2007) 663-672.

[71] K. Iqbal, F. Liu, C.-X. Gong, I. Grundke-Iqbal, Tau in Alzheimer disease and related tauopathies, Curr. Alzheimer Res. 7 (2010) 656-664.

[72] X. Du, S. Qiu, Z. Wang, R. Wang, C. Wang, J. Tian, Q. Liu, Direct interaction between selenoprotein P and tubulin, Int. J. Mol. Sci. 15 (2014) 10199-10214.

[73] B. Michalke, A. Berthele, Contribution to selenium speciation in cerebrospinal fluid samples, J. Anal. At. Spectrom. 26 (2011) 165-170.

[74] C. Méplan, Selenium and chronic diseases: a nutritional genomics perspective, Nutrients 7 (2015) 3621-3651.

[75] C. Méplan, L.K. Crosley, F. Nicol, G.J. Beckett, A.F. Howie, K.E. Hill, G. Horgan, J.C. Mathers, J.R. Arthur, J.E. Hesketh, Genetic polymorphisms in the human selenoprotein $\mathrm{P}$ gene determine the response of selenoprotein markers to selenium supplementation in a gender-specific manner (the SELGEN study), FASEB J. 21 (2007) 3063-3074.

[76] B.R. Cardoso, A.L. Busse, D.J. Hare, C. Cominetti, M.A. Horst, G. McColl, R.M. Magaldi, W. Jacob-Filho, S.M. Cozzolino, Pro198Leu polymorphism affects the selenium status and GPx activity in response to Brazil nut intake, Food Funct. 7 (2016) 825-833.

[77] C. Méplan, F. Nicol, B.T. Burtle, L.K. Crosley, J.R. Arthur, J.C. Mathers, J.E. Hesketh, Relative abundance of selenoprotein P isoforms in human plasma depends on genotype, se intake, and cancer status, Antioxid. Redox Signal. 11 (2009) 2631-2640.

[78] T. Garcia, J. Esparza, M.R. Nogués, M. Romeu, J. Domingo, M. Gómez, Oxidative stress status and RNA expression in hippocampus of an animal model of Alzheimer's disease after chronic exposure to aluminum, Hippocampus 20 (2010) $218-225$.

[79] S. Zhang, C. Rocourt, W.H. Cheng, Selenoproteins and the aging brain, Mech. Ageing Dev. 131 (2010) 253-260.

[80] A. Dominiak, A. Wilkaniec, P. Wroczyński, A. Adamczyk, Selenium in the therapy 
of neurological diseases. Where is it going? Curr. Neuropharmacol. 14 (2016) $282-299$.

[81] F.P. Bellinger, M.T. Bellinger, L.A. Seale, A.S. Takemoto, A.V. Raman, T. Miki, A.B. Manning-Bog, M.J. Berry, L.R. White, G.W. Ross, Glutathione Peroxidase 4 is associated with neuromelanin in substantia nigra and dystrophic axons in putamen of Parkinson's brain (Article Number 8), Mol. Neurodegener. 6 (2011) (Article Number 8).

[82] R. Brigelius-Flohe, M. Maiorino, Glutathione peroxidases, Biochim. Biophys. Acta 1830 (2013) 3289-3303.

[83] I. Ingold, C. Berndt, S. Schmitt, S. Doll, G. Poschmann, K. Buday, A. Roveri, X. Peng, F. Porto Freitas, T. Seibt, L. Mehr, M. Aichler, A. Walch, D. Lamp, M. Jastroch, S. Miyamoto, W. Wurst, F. Ursini, E. S. J. Arnér, N. Fradejas-Villar, U. Schweizer, H. Zischka, J. P. Friedmann Angeli, M. Conrad, Selenium Utilization by GPX4 Is Required to Prevent Hydroperoxide-Induced Ferroptosis, Cell, 172, 2018, 409-422.e21 doi: http://dx.doi.org/10.1016/j.cell.2017.11.048.

[84] P. Chen, C. Wang, X. Ma, Y. Zhang, Q. Liu, S. Qiu, Q. Liu, J. Tian, J. Ni, Direct interaction of Selenoprotein R with clusterin and its possible role in Alzheimer's disease, PLoS One 8 (2013) e66384.

[85] D.Y. Hwang, J.S. Cho, J.H. Oh, S.B. Shim, S.W. Jee, S.H. Lee, S.J. Seo, S.K. Lee, S.H. Lee, Y.K. Kim, Differentially expressed genes in transgenic mice carrying human mutant presenilin-2 (N141I): correlation of selenoprotein M with Alzheimer's disease, Neurochem. Res. 30 (2005) 1009-1019.

[86] X. Qiao, J. Tian, P. Chen, C. Wang, J. Ni, Q. Liu, Galectin-1 is an interactive protein of selenoprotein M in the brain, Int. J. Mol. Sci. 14 (2013) 22233-22245.

[87] P. Chen, R.R. Wang, X.J. Ma, Q. Liu, J.Z. Ni, Different forms of Selenoprotein M differentially affect Abeta aggregation and ROS generation, Int. J. Mol. Sci. 14 (2013) 4385-4399.

[88] R.H. Rueli, D.J. Torres, A.S. Dewing, A.C. Kiyohara, S.M. Barayuga, M.T. Bellinger, J.H. Uyehara-Lock, L.R. White, P.I. Moreira, M.J. Berry, G. Perry, F.P. Bellinger, S. Selenoprotein, Reduces endoplasmic reticulum stress-induced phosphorylation of tau: potential role in selenate mitigation of tau pathology, J. Alzheimers Dis. 55 (2017) 749-762.

[89] A. Torres-Vega, B.F. Pliego-Rivero, G.A. Otero-Ojeda, L.M. Gomez-Olivan, P. Vieyra-Reyes, Limbic system pathologies associated with deficiencies and excesses of the trace elements iron, zinc, copper, and selenium, Nutr. Rev. 70 (2012) 679-692.

[90] N. Solovyev, M. Vinceti, P. Grill, J. Mandrioli, B. Michalke, Redox speciation of iron, manganese, and copper in cerebrospinal fluid by strong cation exchange chromatography - sector field inductively coupled plasma mass spectrometry, Anal. Chim. Acta 973 (2017) 25-33.

[91] X. Du, H. Li, Z. Wang, S. Qiu, Q. Liu, J. Ni, Selenoprotein P and selenoprotein M block Zn2 + -mediated Abeta42 aggregation and toxicity, Metallomics 5 (2013) 861-870.

[92] M.A.K. Khan, F. Wang, Mercury-selenium compounds and their toxicological significance: toward a molecular understanding of the mercury-selenium antagonism, Environ. Toxicol. Chem. 28 (2009) 1567-1577.

[93] I. Messaoudi, M. Banni, L. Saïd, K. Saïd, A. Kerkeni, Involvement of selenoprotein $\mathrm{P}$ and GPx4 gene expression in cadmium-induced testicular pathophysiology in rat, Chem.-Biol. Interact. 188 (2010) 94-101.

[94] C.D. Syme, R.C. Nadal, S.E.J. Rigby, J.H. Viles, Copper binding to the amyloid- $\beta$ (aß) peptide associated with Alzheimer's disease: folding, coordination geometry, $\mathrm{pH}$ dependence, stoichiometry, and affinity of A $3-(1-28)$ : insights from a range of complementary spectroscopic techniques, J. Biol. Chem. 279 (2004) 18169-18177.

[95] Q.F. Ma, J. Hu, W.H. Wu, H.D. Liu, J.T. Du, Y. Fu, Y.W. Wu, P. Lei, Y.F. Zhao, Y.M. Li, Characterization of copper binding to the peptide amyloid- $\beta(1-16)$ associated with Alzheimer's disease, Biopolymers 83 (2006) 20-31.

[96] A. Olofsson, M. Lindhagen-Persson, M. Vestling, A.E. Sauer-Eriksson, A. Öhman, Quenched hydrogen/deuterium exchange NMR characterization of amyloid- $\beta$ peptide aggregates formed in the presence of Cu2 + or Zn2 +, FEBS J. 276 (2009) 4051-4060.

[97] O. Myhre, H. Utkilen, N. Duale, G. Brunborg, T. Hofer, Metal dyshomeostasis and inflammation in Alzheimer's and Parkinson's diseases: possible impact of environmental exposures, Oxid. Med Cell Longev. 2013 (2013) 726954.

[98] L. Zhao, J.L. Wang, Y.R. Wang, X.Z. Fa, Apigenin attenuates copper-mediated $\beta$ amyloid neurotoxicity through antioxidation, mitochondrion protection and MAPK signal inactivation in an AD cell model, Brain Res. 1492 (2013) 33-45.

[99] C.D. Syme, J.H. Viles, Solution 1H NMR investigation of Zn2 + and Cd $2+$ binding to amyloid-beta peptide (A $\beta$ ) of Alzheimer's disease, BBA-Proteins Proteom. 1764 (2006) 246-256.

[100] S. Furlan, G. La Penna, Modeling of the Zn2 + binding in the 1-16 region of the amyloid $\beta$ peptide involved in Alzheimer's disease, Phys. Chem. Chem. Phys. 11 (2009) 6468-6481.

[101] X. Li, Y. Lv, S. Yu, H. Zhao, L. Yao, The effect of cadmium on A $\beta$ levels in APP/PS1 transgenic mice, Exp. Ther. Med. 4 (2012) 125-130.

[102] J. Mutter, A. Curth, J. Naumann, R. Deth, H. Walach, Does inorganic mercury play a role in Alzheimer's disease? A systematic review and an integrated molecular mechanism, J. Alzheimers Dis. 22 (2010) 357-374.

[103] W. Linert, H. Kozlowski, Metal Ions in Neurological Systems, Springer-Verlag Wien, Vienna, 2012.

[104] X. Du, Y. Zheng, Z. Wang, Y. Chen, R. Zhou, G. Song, J. Ni, Q. Liu, Inhibitory act of selenoprotein $\mathrm{P}$ on $\mathrm{Cu}(+) / \mathrm{Cu}(2+)$-induced tau aggregation and neurotoxicity, Inorg. Chem. 53 (2014) 11221-11230.

[105] W.M. Valentine, K.E. Hill, L.M. Austin, H.L. Valentine, D. Goloowitz, R.F. Burk, Brainstem axonal degeneration in mice with deletion of selenoprotein P, Toxicol. Pathol. 33 (2005) 570-576.
[106] J. Bang, M. Jang, J.H. Huh, J.W. Na, M. Shim, B.A. Carlson, R. Tobe, P.A. Tsuji, V.N. Gladyshev, D.L. Hatfield, B.J. Lee, Deficiency of the 15-kDa selenoprotein led to cytoskeleton remodeling and non-apoptotic membrane blebbing through a RhoA/ROCK pathway, Biochem. Biophys. Res. Commun. 456 (2015) 884-890.

[107] F.P. Bellinger, Q.P. He, M.T. Bellinger, Y.L. Lin, A.V. Raman, L.R. White, M.J. Berry, Association of Selenoprotein P with Alzheimer's pathology in human cortex, J. Alzheimers Dis. 15 (2008) 465-472.

[108] Y. Zhang, Y. Zhou, U. Schweizer, N.E. Savaskan, D. Hua, J. Kipnis, D.L. Hatfield, V.N. Gladyshev, Comparative analysis of selenocysteine machinery and selenoproteome gene expression in mouse brain identifies neurons as key functional sites of selenium in mammals, J. Biol. Chem. 283 (2008) 2427-2438.

[109] A. Nakayama, K.E. Hill, L.M. Austin, A.K. Motley, R.F. Burk, All regions of mouse brain are dependent on selenoprotein P for maintenance of selenium, J. Nutr. 137 (2007) 690-693.

[110] W.M. Valentine, T.W. Abel, K.E. Hill, L.M. Austin, R.F. Burk, Neurodegeneration in mice resulting from loss of functional selenoprotein $\mathrm{P}$ or its receptor apolipoprotein E receptor 2, J. Neuropathol. Exp. Neurol. 67 (2008) 68-77.

[111] S.W. Caito, D. Milatovic, K.E. Hill, M. Aschner, R.F. Burk, W.M. Valentine, Progression of neurodegeneration and morphologic changes in the brains of juvenile mice with selenoprotein P deleted, Brain Res. 1398 (2011) 1-12.

[112] M.M. Peters, K.E. Hill, R.F. Burk, E.J. Weeber, Altered hippocampus synaptic function in selenoprotein P deficient mice, Mol. Neurodegener. 1 (2006) (Article Number 12).

[113] U. Schweizer, M. Michaelis, J. Kohrle, L. Schomburg, Efficient selenium transfer from mother to offspring in selenoprotein-P-deficient mice enables dose-dependent rescue of phenotypes associated with selenium deficiency, Biochem. J. 378 (2004) 21-26.

[114] M.W. Pitts, A.V. Raman, A.C. Hashimoto, C. Todorovic, R.A. Nichols, M.J. Berry, Deletion of selenoprotein P results in impaired function of parvalbumin interneurons and alterations in fear learning and sensorimotor gating, Neuroscience 208 (2012) 58-68.

[115] M.M. Behrens, S.S. Ali, D.N. Dao, J. Lucero, G. Shekhtman, K.L. Quick, L.L. Dugan, Ketamine-induced loss of phenotype of fast-spiking interneurons is mediated by NADPH-oxidase, Science 318 (2007) 1645-1647.

[116] M.M. Behrens, S.S. Ali, L.L. Dugan, Interleukin-6 mediates the increase in NADPHOxidase in the Ketamine Model of Schizophrenia, J. Neurosci. 28 (2008) $13957-13966$.

[117] X. Wang, Z.Q. Zhou, C. Yang, J.G. Xu, J.J. Yang, Nuclear factor-kappa B is involved in the phenotype loss of parvalbumin-interneurons in vitro, Neuroreport 22 (2011) 264-268.

[118] N.E. Savaskan, A.U. Brauer, M. Kuhbacher, I.Y. Eyupoglu, A. Kyriakopoulos, O. Ninnemann, D. Behne, R. Nitsch, Selenium deficiency increases susceptibility to glutamate-induced excitotoxicity, FASEB J. 17 (2003) 112-114.

[119] P.R. Hoffmann, S.C. Hoge, P.A. Li, F.W. Hoffmann, A.C. Hashimoto, M.J. Berry, The selenoproteome exhibits widely varying, tissue-specific dependence on selenoprotein P for selenium supply, Nucleic Acids Res. 35 (2007) 3963-3973.

[120] M.R. Ashrafi, R. Shabanian, A. Abbaskhanian, A. Nasirian, M. Ghofrani, M. Mohammadi, G.R. Zamani, Z. Kayhanidoost, S. Ebrahimi, Z. Pourpak, Selenium and intractable epilepsy: is there any correlation? Pediatr. Neurol. 36 (2007) 25-29.

[121] M. Seven, S.Y. Basaran, M. Cengiz, S. Unal, A. Yuksel, Deficiency of selenium and zinc as a causative factor for idiopathic intractable epilepsy, Epilepsy Res. 104 (2013) 35-39.

[122] G. Fiskum, C.A. Danilov, Z. Mehrabian, L.L. Bambrick, T. Kristian, M.C. McKenna, I. Hopkins, E.M. Richards, R.E. Rosenthal, Postischemic oxidative stress promotes mitochondrial metabolic failure in neurons and astrocytes, Ann. NY Acad. Sci. (2008) 129-138.

[123] G.E. Landreth, E.G. Reed-Geaghan, Toll-Like receptors in Alzheimer's disease, in: T. Kielian (Ed.), Toll-Like Receptors: Roles in Infection and Neuropathology, 2009, pp. 137-153.

[124] F.P. Bellinger, A.V. Raman, M.A. Reeves, M.J. Berry, Regulation and function of selenoproteins in human disease, Biochem. J. 422 (2009) 11-22.

[125] O. Agamy, B. Ben Zeev, D. Lev, B. Marcus, D. Fine, D. Su, G. Narkis, R. Ofir, C. Hoffmann, E. Leshinsky-Silver, H. Flusser, S. Sivan, D. Soll, T. Lerman-Sagie, O.S. Birk, Mutations disrupting selenocysteine formation cause progressive cerebello-cerebral atrophy, Am. J. Hum. Genet. 87 (2010) 538-544.

[126] J.H. Ellwanger, S.I.R. Franke, D.L. Bordin, D. Prá, J.A.P. Henriques, Biological functions of selenium and its potential influence on Parkinson's disease, Ann. Braz. Acad. Sci. 88 (2016) 1655-1674.

[127] J. Aaseth, J. Alexander, G. Bjørklund, K. Hestad, P. Dusek, P.M. Roos, U. Alehagen, Treatment strategies in Alzheimer's disease: a review with focus on selenium supplementation, Biometals 29 (2016) 827-839.

[128] C. Berr, B. Balansard, J. Arnaud, A.M. Roussel, A. Alperovitch, Cognitive decline is associated with systemic oxidative stress: the EVA study. Etude du Vieillissement Arteriel, J. Am. Geriatr. Soc. 48 (2000) 1285-1291.

[129] C. Berr, J. Arnaud, T.N. Akbaraly, Selenium and cognitive impairment: a briefreview based on results from the EVA study, BioFactors 38 (2012) 139-144.

[130] A.J. Perkins, H.C. Hendrie, C.M. Callahan, S. Gao, F.W. Unverzagt, Y. Xu, K.S. Hall, S.L. Hui, Association of antioxidants with memory in a multiethnic elderly sample using the Third National Health and Nutrition Examination survey, Am. J. Epidemiol. 150 (1999) 37-44.

[131] N.T. Akbaraly, I. Hininger-Favier, I. Carrière, J. Arnaud, V. Gourlet, A.M. Roussel, C. Berr, Plasma selenium over time and cognitive decline in the elderly, Epidemiology 18 (2007) 52-58.

[132] S. Gao, Y. Jin, K.S. Hall, C. Liang, F.W. Unverzagt, R. Ji, J.R. Murrell, J. Cao, J. Shen, F. Ma, J. Matesan, B. Ying, Y. Cheng, J. Bian, P. Li, H.C. Hendrie, Selenium 
level and cognitive function in rural elderly Chinese, Afr. J. Pharm. Pharm. 165 (2007) 955-965.

[133] B.R. Cardoso, T.P. Ong, W. Jacob-Filho, O. Jaluul, M.I. Freitas, S.M. Cozzolino, Nutritional status of selenium in Alzheimer's disease patients, Br. J. Nutr. 103 (2010) 803-806.

[134] B.R. Cardoso, V. Silva Bandeira, W. Jacob-Filho, S.M. Franciscato Cozzolino, Selenium status in elderly: relation to cognitive decline, J. Trace Elem. Med. Biol. 28 (2014) 422-426.

[135] B.R. Cardoso, D.J. Hare, A.I. Bush, Q.X. Li, C.J. Fowler, C.L. Masters, R.N. Martins, K. Ganio, A. Lothian, S. Mukherjee, E.A. Kapp, B.R. Roberts, Selenium levels in serum, red blood cells, and cerebrospinal fluid of Alzheimer's disease patients: a report from the Australian Imaging, Biomarker \& Lifestyle Flagship Study of Ageing (AIBL), J. Alzheimers Dis. 57 (2017) 183-193.

[136] K. Hesse-Bähr, I. Dreher, J. Köhrle, The influence of the cytokines II-1 ßand INF on the expression of selenoproteins in the human hepatocarcinoma cell line HepG2, BioFactors 11 (2000) 83-85.

[137] C. Holmes, Review: systemic inflammation and Alzheimer's disease, Neuropathol. Appl. Neurobiol. 39 (2013) 51-68.

[138] L.H. Duntas, A. Hubalewska-Dydejczyk, Selenium and inflammation-potential use and future perspectives, US Endocrinol. 11 (2015) 97-102.

[139] L. Wiehe, M. Cremer, M. Wisniewska, N.-P. Becker, E. Rijntjes, J. Martitz, S. Hybsier, K. Renko, C. Bührer, L. Schomburg, Selenium status in neonates with connatal infection, Br. J. Nutr. 116 (2016) 504-513.

[140] L. Gerhardsson, T. Lundh, L. Minthon, E. Londos, Metal concentrations in plasma and cerebrospinal fluid in patients with Alzheimer's disease, Dement Geriatr. Cogn. Disord. 25 (2008) 508-515.

[141] L. Gerhardsson, T. Lundh, E. Londos, L. Minthon, Cerebrospinal fluid/plasma quotients of essential and non-essential metals in patients with Alzheimer's disease, J. Neural Transm. 118 (2011) 957-962.

[142] S.M. Lippman, E.A. Klein, P.J. Goodman, M.S. Lucia, I.M. Thompson, L.G. Ford, H.L. Parnes, L.M. Minasian, J.M. Gaziano, J.A. Hartline, J.K. Parsons, J.D. Bearden, E.D. Crawford, G.E. Goodman, J. Claudio, E. Winquist, E.D. Cook, D.D. Karp, P. Walther, M.M. Lieber, A.R. Kristal, A.K. Darke, K.B. Arnold, P.A. Ganz, R.M. Santella, D. Albanes, P.R. Taylor, J.L. Probstfield, T.J. Jagpal, J.J. Crowley, F.L. Meyskens, L.H. Baker, C.A. Coltman, Effect of selenium and vitamin $\mathrm{E}$ on risk of prostate cancer and other cancers the selenium and vitamin $\mathrm{E}$ cancer prevention trial (SELECT), J. Am. Med Assoc. 301 (2009) 39-51.

[143] R.J. Kryscio, E.L. Abner, A. Caban-Holt, M. Lovell, P. Goodman, A.K. Darke M. Yee, J. Crowley, F.A. Schmitt, Association of antioxidant supplement use and dementia in the prevention of Alzheimer's disease by vitamin $\mathrm{E}$ and selenium trial (PREADViSE), JAMA Neurol. 74 (2017) 567-573.

[144] S. Krishnan, P. Rani, Evaluation of selenium, redox status and their association with plasma amyloid/tau in Alzheimer's disease, Biol. Trace Elem. Res 158 (2014) $158-165$.

[145] B. Ben-Zeev, C. Hoffman, D. Lev, N. Watemberg, G. Malinger, N. Brand, T. LermanSagie, Progressive cerebellocerebral atrophy: a new syndrome with microcephaly, mental retardation, and spastic quadriplegia, J. Med. Genet. 40 (2003) e96.

[146] O.S. Birk, Selenocysteinopathies: progressive cerebello-cerebral atrophy and other diseases of the 21st amino acid, selenocysteine, Future Neurol. 6 (2011) 135-138.

[147] L. Schomburg, U. Schweizer, B. Holtmann, L. Flohe, M. Sendtner, J. Kohrle, Gene disruption discloses role of selenoprotein P in selenium delivery to target tissues, Biochem. J. 370 (2003) 397-402.

[148] G.F. Weber, P. Maertens, X. Meng, C.E. Pippenger, Glutathione peroxidase deficiency and childhood seizures, Lancet 337 (1991) 1443-1444.

[149] V.T. Ramaekers, N. Calomme, D. Vandenberghe, W. Makropoulos, Selenium deficiency triggering intractable seizures, Neuropediatrics 25 (1994) 217-223.

[150] M. Vinceti, A. Chiari, M. Eichmüller, K.J. Rothman, T. Filippini, C. Malagoli, J. Weuve, M. Tondelli, G. Zamboni, P.F. Nichelli, B. Michalke, A selenium species in cerebrospinal fluid predicts conversion to Alzheimer's dementia in persons with mild cognitive impairment, Alzheimer'S. Res. Ther. 9 (2017) 100.

[151] R.J. Kryscio, E.L. Abner, F.A. Schmitt, P.J. Goodman, M. Mendiondo, A. CabanHolt, B.C. Dennis, M. Mathews, E.A. Klein, J.J. Crowley, I. Select, A randomized controlled Alzheimer's disease prevention trial's evolution into an exposure trial: the preadvise trial, J. Nutr. Health Aging 17 (2013) 72-75.

[152] M.J. Christensen, Selenium and prostate cancer prevention: what next-if anything? Cancer Prev. Res. 7 (2014) 781-785.

[153] J. Lü, J. Zhang, C. Jiang, Y. Deng, N. Özten, M.C. Bosland, Cancer chemoprevention research with selenium in the post-SELECT era: promises and challenges, Nutr. Cancer 68 (2016) 1-17.

[154] H.L. Nicastro, B.K. Dunn, selenium and prostate cancer prevention: insights from the selenium and Vitamin E cancer prevention trial (SELECT), Nutrients 5 (2013) $1122-1148$

[155] R. Hurst, C.N. Armah, J.R. Dainty, D.J. Hart, B. Teucher, A.J. Goldson, M.R. Broadley, A.K. Motley, S.J. Fairweather-Tait, Establishing optimal selenium status: results of a randomized, double-blind, placebo-controlled trial, Am. J. Clin. Nutr. 91 (2010) 923-931.

[156] A. Shahar, K.V. Patel, R.D. Semba, S. Bandinelli, D.R. Shahar, L. Ferrucci, J.M. Guralnik, Plasma selenium is positively related to performance in neurological tasks assessing coordination and motor speed, Mov. Disord. 25 (2010) 1909-1915.

[157] M. Amiri, L. Farzin, M.E. Moassesi, F. Sajadi, Serum trace element levels in febrile convulsion, Biol. Trace Elem. Res. 135 (2010) 38-44.

[158] M. Vinceti, B. Burlingame, T. Filippini, A. Naska, A. Bargellini, P. Borella, The epidemiology of selenium and human health, in: D.L. Hatfield, U. Schweizer, P.A. Tsuji, V.N. Gladyshev (Eds.), Selenium: Its Molecular Biology and Role in Human Health, Springer International Publishing, Cham, 2016, pp. 365-376.

[159] S. Sadigh-Eteghad, M. Talebi, M. Farhoudi, Association of apolipoprotein E epsilon 4 allele with sporadic late onset alzheimer's disease: a meta-analysis, Neurosciences 17 (2012) 321-326.

[160] R. Rueli, A.C. Parubrub, A.S.T. Dewing, A.C. Hashimoto, M.T. Bellinger, E.J. Weeber, J.H. Uyehara-Lock, L.R. White, M.J. Berry, F.P. Bellinger, Increased Selenoprotein P in choroid plexus and cerebrospinal fluid in Alzheimer's disease brain, J. Alzheimers Dis. 44 (2015) 379-383.

[161] M.O. Krebs, J.M. Desce, M.L. Kemel, C. Gauchy, G. Godeheu, A. Cheramy, J. Glowinski, Glutamatergic control of dopamine release in the rat striatum evidence for presynaptic N-methyl-D-aspartate receptors on dopaminergic nerveterminals, J. Neurochem. 56 (1991) 81-85.

[162] U. Beffert, E.J. Weeber, A. Durudas, S. Qiu, I. Masiulis, J.D. Sweatt, W.P. Li, G. Adelmann, M. Frotscher, R.E. Hammer, J. Herz, Modulation of synaptic plasticity and memory by Reelin involves differential splicing of the lipoprotein receptor ApoER2, Neuron 47 (2005) 567-579.

[163] E. Jablonska, M. Vinceti, Selenium and human health: witnessing a Copernican revolution? J. Environ. Sci. Health C 33 (2015) 328-368.

[164] G.F. Combs Jr., Biomarkers of selenium status, Nutrients 7 (2015) 2209-2236.

[165] A.J. Duffield-Lillico, M.E. Reid, B.W. Turnbull, G.F. Combs, E.H. Slate, L.A. Fischbach, J.R. Marshall, L.C. Clark, Baseline characteristics and the effect of selenium supplementation on cancer incidence in a randomized clinical trial, Cancer Epidemiol. Biomark. Prev. 11 (2002) 630.

[166] A.R. Kristal, A.K. Darke, J.S. Morris, C.M. Tangen, P.J. Goodman, I.M. Thompson, J.F.L. Meyskens, G.E. Goodman, L.M. Minasian, H.L. Parnes, S.M. Lippman, E.A. Klein, Baseline selenium status and effects of selenium and vitamin E supplementation on prostate cancer risk, JNCI-J. Natl. Cancer I 106 (2014) (djt456djt456).

[167] M.P. Rayman, K.H. Winther, R. Pastor-Barriuso, F. Cold, M. Thvilum, S. Stranges, E. Guallar, S. Cold, Effect of long-term selenium supplementation on mortality: results from a multiple-dose, randomised controlled trial (this issue), Free Radic Biol. Med. (2018), http://dx.doi.org/10.1016/j.freeradbiomed.2018.02.015. 